\title{
Integral Benchmark Data for Nuclear Data Testing Through the ICSBEP \& IRPhEP
}

\section{International Conference Dedicated to the Fiftieth Anniversary of the ABBN Nuclear Data System (ABBN-50)}

\author{
J. Blair Briggs \\ John D. Bess \\ Jim Gulliford
}

\section{October 2013}

The INL is a

U.S. Department of Energy

National Laboratory

operated by

Battelle Energy Alliance

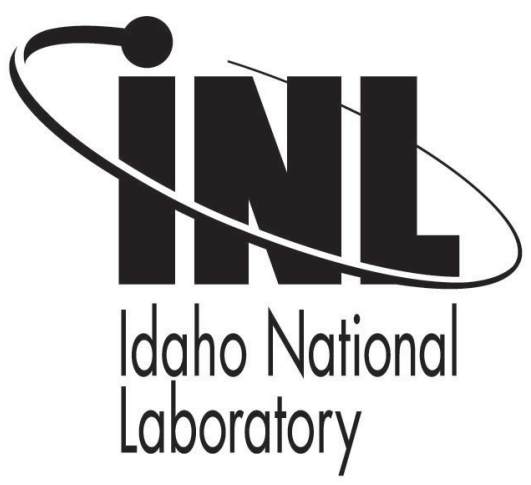

This is a preprint of a paper intended for publication in a journal or proceedings. Since changes may be made before publication, this preprint should not be cited or reproduced without permission of the author. This document was prepared as an account of work sponsored by an agency of the United States Government. Neither the United States Government nor any agency thereof, or any of their employees, makes any warranty, expressed or implied, or assumes any legal liability or responsibility for any third party's use, or the results of such use, of any information, apparatus, product or process disclosed in this report, or represents that its use by such third party would not infringe privately owned rights. The views expressed in this paper are not necessarily those of the United States Government or the sponsoring agency. 


\title{
Integral Benchmark Data for Nuclear Data Testing Through the ICSBEP \& IRPhEP
}

\author{
J. Blair Briggs,${ }^{1, *}$ John D. Bess,${ }^{1}$ and Jim Gulliford ${ }^{2}$ \\ ${ }^{1}$ Idaho National Laboratory, 2525 North Fremont, Idaho Falls, Idaho 83415-3860, U.S.A. \\ ${ }^{2}$ Organization for Economic Cooperation and Development (OECD) Nuclear Energy Agency (NEA), \\ Le Seine St-Germain, 12 Boulevard des Iles, 92130 Issy-Les-Moulineaux, France
}

\begin{abstract}
The status of the International Criticality Safety Benchmark Evaluation Project (ICSBEP) and International Reactor Physics Experiment Evaluation Project (IRPhEP) was last discussed directly with the nuclear data community at ND2007. Since ND2007, integral benchmark data that are available for nuclear data testing have increased significantly. The status of the ICSBEP and the IRPhEP is discussed and selected benchmark configurations that have been added to the ICSBEP and IRPhEP Handbooks since ND2007 are highlighted.
\end{abstract}

\section{INTRODUCTION}

The status of the International Criticality Safety Benchmark Evaluation Project (ICSBEP) and International Reactor Physics Experiment Evaluation Project (IRPhEP) was last discussed directly with the nuclear data community at ND2007. Since ND2007, integral benchmark data that are available for nuclear data testing have increased significantly as evidenced by the level of use of the ICSBEP Handbook for nuclear data testing of the most recently released Evaluated Nuclear Data Files, ENDF/B-VII.1 [1]. The contents of the International Handbook of Evaluated Criticality Safety Benchmark Experiments [2] (ICSBEP Handbook) have increased from 442 evaluations (38,000 pages) containing benchmark specifications for 3,955 critical, subcritical, or $k_{\infty}$ configurations to 549 evaluations (nearly 65,000 pages) containing benchmark specifications for 4,708 configurations. Approximately 15 new evaluations and 150 additional configurations are expected to be added to the 2013 edition of the Handbook.

Since ND2007 the contents of the International Handbook of Evaluated Reactor Physics Benchmark Experiments [3] (IRPhEP Handbook) have increased from 16 different experimental series that were performed at 12 different reactor facilities to 56 experimental series that were performed at 32 different nuclear facilities. The 2013 edition of the IRPhEP Handbook, scheduled for publication in late March, will contain 65 experimental series performed at 34 different nuclear facilities. Significant additions of reactor-physics measurement data have also been made to previously published IRPhEP evaluations and additional reactor data have been copied from the

\footnotetext{
* Corresponding author: j.briggs@inl.gov
}

ICSBEP Handbook to the IRPhEP Handbook to consolidate reactor physics data. With those additions, the 2013 edition of the IRPhEP Handbook will contain data from 131 different experimental series that were performed at 47 different nuclear facilities.

A considerable number of improvements and quality checks have been made to the ICSBEP searchable database, DICE, and a new database, IDAT, has been created for the IRPhEP Handbook. Those databases make it much easier to locate data of interest than simple word searches of the PDF files in the two Handbooks.

Twenty-four countries have contributed to those two projects, 20 to the ICSBEP and 19 to the IRPhEP. Contributors are: Argentina, Belgium, Brazil, Canada, China, Czech Republic, France, Germany, Hungary, India, Israel, Italy, Japan, Kazakhstan, Korea (Republic of), Poland, Russian Federation, Serbia, Slovenia, Spain, Sweden, Switzerland, United Kingdom, and United States.

The purpose of the ICSBEP and the IRPhEP is to provide extensively peer-reviewed integral benchmark data that can be used by the international nuclear data community for testing and improvement of nuclear data files and by the international reactor-physics, criticality safety, and math \& computation communities for validation of analytical methodologies used for reactor physics, fuel cycle, nuclear facility safety analysis and design, and advanced modeling and simulation efforts.

\section{THE 2012 EDITION OF THE ICSBEP AND 2013 EDITION OF THE IRPHEP HANDBOOKS}

\section{A. ICSBEP Handbook}

The ICSBEP Handbook [2] is available on DVD or on the Internet. The DVD version and/or on- 
line access can be requested at http://icsbep.inl.gov or http://www.oecd-nea.org/science/wpncs/icsbep/. Included in the 2012 edition are benchmark specifications for the following:

- $723 \mathrm{Pu}$ experiments, of which 118 are metal (111 fast, 4 intermediate, 2 thermal, and 1 mixed), 569 solution (thermal), and 36 compound (7 fast, 4 intermediate, 17 thermal, and 8 mixed);

- 1,412 highly-enriched U experiments, of which 580 are metal (390 fast, 15 intermediate, 137 thermal, and 38 mixed), 536 solution (3 intermediate and 533 thermal), 289 compound (10 fast, 14 intermediate, 218 thermal, and 47 mixed), 5 mixed metal/solution (thermal), and 2 compound/solution (thermal);

- 261 intermediate- and mixed-enrichment U experiments, of which 41 are metal (38 fast, and 3 intermediate), 64 solution (thermal), and $156 \mathrm{com}-$ pound ( 2 fast, 18 intermediate, 116 thermal, and 20 mixed);

- 1,545 low-enrichment U experiments, of which 87 are metal (thermal), 117 solution (thermal), 1,281 compound (1 fast, 1275 thermal, and 5 mixed), and 60 mixed compound/solution (thermal);

- $244{ }^{233} \mathrm{U}$ experiments, of which 11 are metal (10 fast, 1 thermal), 227 solution (190 thermal, 29 intermediate, and 8 mixed), and 6 compound (thermal);

- 503 mixed $\mathrm{Pu}-\mathrm{U}$ experiments, of which 53 are metal (48 fast, 4 intermediate, and 1 mixed), 72 solution (thermal), and 301 compound (7 fast, 3 intermediate, 274 thermal, and 17 mixed), 56 mixed compound/solution systems (thermal), and 21 mixed metal/compound (13 fast and 8 mixed);

- 20 special isotope experiments, all of which are metal (fast) $\left({ }^{244} \mathrm{Cm},{ }^{238} \mathrm{Pu},{ }^{237} \mathrm{~Np}\right.$, and $\left.{ }^{242} \mathrm{Pu}\right)$;

- 6 criticality-alarm/shielding benchmarks containing 24 configurations with numerous dose points;

- 6 fundamental physics benchmark, which includes 155 fission-rate and transmission measurements and reaction rate ratios for 45 different materials.

\section{B. IRPhEP Handbook}

The IRPhEP Handbook [3] is available only on DVD. The DVD version can be requested at http://irphep.inl.gov or http://www.oecdnea.org/science/wprs/irphe/irphe-handbook. Included in the 2013 edition are benchmark specifications for the following reactors or assemblies that simulate certain reactor characteristics:
- 6 PWR: CREOLE/EOLE, DIMPLE, DUKE Power, OTTOHAHN, SCCR, VENUS

- 3 VVER: P-Facility, ZR-6, LR-0

- 0 BWR:

- 9 LMFR: BFS-1, BFS-2, BR-2, FFTF, JOYO, SNEAK, ZEBRA, ZPPR, ZPR

- 5 GCR: ASTRA, HTR-10, HTTR, PROTEUS, VHTRC

- 0 GCFR:

- 5 LWR: CROCUS, DIMPLE, IPEN(MB01), KRITZ, TCA

- 3 HWR: DCA, ETA, ZED2

- 0 MSR:

- 1 RBMK: RBMK $(\mathrm{CF})$

- 5 SPACE: SCCA, TOPAZ, UKS1M, ZPR, ZPPR

- 16 FUND: ATR, BFS-1, BFS-2, CORAL-1, FRO, HECTOR, IGR, LAMPRE, NRAD, PBF, RA-6, RB, RHF, TRIGA, ZPR, ZEBRA

\section{SELECTED BENCHMARK SPECIFICATIONS (ADDED SINCE ND2007) THAT ARE PARTICULARLY USEFUL FOR NUCLEAR DATA TESTING}

Benchmark specifications for nearly 1,000 experimental configurations have been added to the ICSBEP and IRPhEP Handbooks since ND2007. Some of those experiments that are particularly useful for nuclear data testing are highlighted in this section. The experiments are broken into fissile material type and non-fissile materials.

\section{A. Plutonium Data}

Five experimental series (44 configurations) with plutonium metal, oxide, or solution, have been added. Included are IPPE's BR-2 plutonium-metal-fuelled, mercury-cooled fast reactor (PU-MET-FAST-046) [2]; BARC's PURNIMA-I plutonium-oxide-fuelled fast reactor with molybdenum, copper, and mild steel reflectors (PU-COMP-FAST-004) [2]; IRSN's/CEA's plutonium $\left(19 \%{ }^{240} \mathrm{Pu}\right)$ nitrate solution $\left.21-102 \mathrm{~g} / \mathrm{l}\right)$ with hafnium plates (PU-SOL-THERM-031) [2]; and IRSN's/CEA's low concentrated $(14-20 \mathrm{~g} / \mathrm{l})$ plutonium nitrate solution at room temperature (PU-SOL-THERM-038) [2]. The latter plutonium solution experiment is part of the IRSN Plutonium Temperature Effect Program. Additional data from that program $\left(28^{\circ} \mathrm{C}-40^{\circ} \mathrm{C}\right)$ are planned for evaluation and publication in 2013. 


\section{B. Highly Enriched Uranium Data}

Thirty-six experimental series (119 configurations) with HEU metal, oxide, or solution, have been added. Many of those experiments were performed to specifically test various structural materials and are discussed further in Section III.H, Non-Fissile Material Data.

Also included are three series of very precisely measured space-reactor experiments performed at ORNL with lattices of highly enriched $\mathrm{UO}_{2}$ fuel rods reflected by graphite (SCCA-SPACE-EXP-001 and -002) [3] or beryllium (SCCA-SPACE-EXP-003) [3]. Those experiments are simple with very small uncertainties and include benchmark specifications for reactivity effects and reaction rate distribution measurements, in addition to critical configuration measurements.

Also included are BAPL's ETA-I $\mathrm{D}_{2} \mathrm{O}$ moderated $\mathrm{UO}_{2}-\mathrm{ThO}_{2}$ lattice experiments (HEU-COMP-THERM018) [2] that were designed to provide a clean test of the adequacy of epithermal cross section data for ${ }^{235} \mathrm{U}$ and ${ }^{232}$ Th.

Three series of uranium fluoride solution experiments have also been evaluated and added to the ICSBEP Handbook (HEU-SOL-THERM-034, -047, and -048) [2]. Two series involve interactions among multiple units and one series simulated and infinite slab of highly concentrated HEU solution.

\section{Intermediate Enriched Uranium Data}

Eighteen experimental series (169 configurations) with IEU metal, compound (oxide, hydride, fluoride) or solution have been added. A significant portion (136 configurations) of the newly contributed IEU data are from the Aldermaston and Dounreay facilities in the United Kingdom and are predominately uranium/hydrogen systems at $\sim 30 \%{ }^{235} \mathrm{U}$ enrichment. Data from Dounreay include $\mathrm{UO}_{2} \mathrm{~F}_{2}$ aqueous solutions in cylindrical, slab, spherical, and hemispherical geometries and cover an $\mathrm{H}:{ }^{235} \mathrm{U}$ atomic ratio range from about 50 upwards (IEU-SOLTHERM-002, and -003) [2]. Data from Aldermaston include solid $\mathrm{UO}_{2}$-wax compacts at $\mathrm{H}^{235} \mathrm{U}$ ratios between about 8 and 80 (IEU-COMP-THERM-015, -016; IEUCOMP-INTER-006; and IEU-COMP-MIXED-004) [2]. Most of those experiments have thermal energy spectra; however, a few configurations have mixed or intermediate energy spectra. Benchmark models are simple geometries with uncertainties that range from 300 to 1100 pcm.

Also included are benchmark specifications for three of the historical ANL CSEWG benchmarks, ZPR-3 Assemblies 6F (47 Atom \% - IEU-MET-FAST-015) [2], 11 (12 Atom \% - IEU-MET-FAST-016) [2], and 12 (21 Atom \% - IEU-COMP-FAST-004) [2]. Those assemblies comprise HEU and Depleted Uranium to simulate the desired enrichment. Assembly 6F simulates spherical geometry, Assemblies 11 and 12 simulate cylindrical geometry. Benchmark models are simple geometry with uncertainties of $\sim 150$ pcm.

Other IEU benchmark experiments include the INL PBF Reactor $\left(\mathrm{U}(18) \mathrm{O}_{2}-\mathrm{CaO}-\mathrm{ZrO}_{2}\right.$ Fuel Rods in Water - IEU-COMP-THERM-009) [2], INL NRAD Reactor (Uranium(20)-Erbium-Zirconium-Hydride Fuel IEU-COMP-THERM-013) [2], CNEA RA-6 Reactor $\left(\mathrm{U}(19.77)_{3} \mathrm{Si}_{2}\right.$-Al Fuel Plates - IEU-COMP-THERM014) [2]; FR0 Series 1: (Copper-Reflected Uranium (20\% ${ }^{235}$ U) Metal - IEU-MET-FAST-020, -021, -022, and IEUMET-INTER-001); and ORNL $\mathrm{UF}_{4}-\mathrm{CF}_{4}$ Blocks (12.5, 18.8, 25, and $30 \%{ }^{235} \mathrm{U}$ IEU-COMP-INTER-004 and IEU-COMP-MIXED-002) [2].

\section{Low Enriched Uranium Data}

Twenty-three experimental series (271 configurations) with LEU metal, oxide, or solution have been added. Included are six evaluations (64 configurations) of experiments performed on IPEN's MB-01 Reactor. Varying parameters include a heavy Type 304 stainless steel reflector (LEU-COMP-THERM-043) [2]; stainless steel, copper, and $\mathrm{UO}_{2}-\mathrm{Gd}_{2} \mathrm{O}_{3}$ rods (LEU-COMP-THERM-044 and -054) [2]; large voids in the reflector (LEU-COMPTHERM-058) [2]; soluble boron (LEU-COMP-THERM092) [2]; and temperature variations from $14^{\circ} \mathrm{C}-85^{\circ} \mathrm{C}$ (LEU-COMP-THERM-046). Uncertainties range from $40-100$ pcm.

Also included are benchmark specifications for AECL's ZED-2 Reactor natural-uranium metal fuel assemblies in heavy-water (LEU-MET-THERM-003 [2] and ZED2HWR-EXP-001 [3]); IRSN's/CEA's $\mathrm{UO}_{2} \quad\left(4.7 \%{ }^{235} \mathrm{U}\right)$ under-moderated rod lattices (LEU-COMP-THERM-072 and -073) [2] and dry storage configurations (LEUCOMP-THERM-057) [2]; ORNL's water moderated lattices of U-Metal $\left(4.95 \%{ }^{235} \mathrm{U}\right)$ fuel rods with diameters of 0.3 and $2.49 \mathrm{~cm}$ (LEU-MET-THERM-004 and 007) [2]; SNL's water-moderated $7 \%$ enriched $\mathrm{UO}_{2}$ fuel rod lattices (LEU-COMP-THERM-080) [2]; JAEA's 6\% enriched uranyl nitrate solution experiments (LEU-SOLTHERM-011) [2] and 5\% enriched $\mathrm{UO}_{2}$ fuel rod lattices in $6 \%$ enriched uranyl nitrate solution (LEU-MISCTHERM-005, -006, and -007) [2]; Kyoto University's KUCA Reactor erbium oxide experiments (LEU-METTHERM-005) [2], and NRI's LR-0 VVER experiments (LEU-COMP-THERM-087 [2] and LR(0)-VVER-RESR$001[3])$.

\section{E. U-233 Data}

Two experimental series (7 configurations) with ${ }^{233} \mathrm{U}$ oxide or solution have been added. Included are BARC's beryllium-reflected PURNIMA-II ${ }^{233}$ Uranyl Nitrate Solution Reactor (U233-SOL-THERM-007) [2] and the BAPL's ETA-II D $2 \mathrm{O}$ moderated ${ }^{233} \mathrm{UO}_{2^{-}}{ }^{233232} \mathrm{ThO}_{2}$ lattice experiments (U233-COMP-THERM-004) [2]. 


\section{F. Mixed Plutonium/Uranium Data}

Nine experimental series (34 configurations) with mixed plutonium/uranium metal, oxide, or carbide fuels have been added. Included are ANL ZPR-3 Assemblies 48 and 48B(MOX with $\mathrm{C} \& \mathrm{Na}$ and a DU blanket - MIX-COMP-FAST-003 [2]), 53 (MOX with $\mathrm{C}$ and a DU reflector - MIX-MET-INTER-004 [2]), 54 (MOX with $\mathrm{C}$ and an Fe reflector - MIX-MET-INTER-003), and 56B (MOX with Na and a Ni-Na reflector - MIX-COMPFAST-004 [2]); ZPR-9 Assembly 31 (MOX carbide with a DU carbide blanket - MIX-COMP-FAST-005); ZPPR2 (MOX with $\mathrm{Na}$ and a DU, Na, and steel reflector MIX-COMP-FAST-006 [2]) BFS-1 Assemblies 61 (MOX with $\mathrm{C}$ and $\mathrm{Pb}-$ MIX-MET-FAST-006 [2]) and 97 and 99 (MOX with $\mathrm{CH}_{2}$ - MIX-MISC-FAST-004 [2]); and a series of experiments with lattices of PHENIX mixed oxide $\left(\mathrm{Pu} /(\mathrm{U}+\mathrm{Pu})=26 \%,{ }^{240} \mathrm{Pu}\right)$ fuel pins (MIX-COMPTHERM-017) [2]. ZPR-3 Assemblies 48 and 56B, ZPR-9 Assembly 31, and ZPPR-2 are also historical CSEWG benchmarks.

\section{G. Special Isotopes}

The last special isotopic data were contributed several years prior to ND2007. There is nothing new to report in this category.

\section{H. Non-Fissile Material Data}

Nineteen experimental series (40 configurations) with HEU metal with vanadium (HEU-MET-FAST-025, 040, and -042 and HEU-MET-MIXED-016) [2], tungsten (HEU-MET-FAST-049, -050, and -052 and HEUMET-MIXED-017) [2], molybdenum (HEU-MET-FAST092) [2], iron (HEU-MET-FAST-043, -087, and -088, and HEU-MET-MIXED-018) [2] and aluminum (HEU-METFAST-044, -089, and -090 and HEU-MET-MIXED-019) have been added. Those experiments were performed at VNIITF to test the neutronics properties of the test material. The test materials were used as a reflector (various thicknesses), diluent, and diluent mixed with either beryllium or polyethylene to adjust the spectra. Experiments typically have either fast or mixed spectra and benchmark models are simple with uncertainties between
70 and $190 \mathrm{pcm}$.

One experimental series (2 configurations) with watermoderated LEU fuel rod lattices separated by titanium was contributed by IRSN/CEA (LEU-COMP-THERM074) [2]. Those experiments were part of the MIRTE program carried out at the CEA Valduc Center on the Apparatus B assembly.

Two experimental series (3 configurations) with HEU metal with beryllium have also been added. Those experiments were performed at ORNL and included two configurations with HEU metal annuli with the central zone filled with beryllium (HEU-MET-FAST-059) [2] and one configuration in which an HEU metal cylinder with a thick beryllium top-reflector (HEU-MET-FAST-069) [2]. Benchmark models for all three configurations are simple geometries with small uncertainties.

Two experimental series (2 configurations) with HEU metal foils interspersed in polyethylene with rhenium or a Gadolinide alloy (Ni-Cr-Mo-Gd alloy) have also been added. Those experiments were performed at LANL and included two configurations with HEU metal foils and either rhenium foils (HEU-MET-THERM-033) [2] or Gadolinide plates(HEU-MET-THERM-34) [2] interspersed with polyethylene. Both of those configurations are simple with small uncertainties, but calculated values are discrepant. A reference case, $\mathrm{HEU}$ foils with $\mathrm{CH}_{2}$ (HEU-MET-THERM-032) [2], is also available.

\section{CONCLUSIONS}

The ICSBEP and IRPhEP continue to provide highquality integral benchmark data from around the world that are of great value for Nuclear Data testing, uncertainty reduction. Twenty-four countries have contributed to the projects. Data will be of value for future decades.

The ICSBEP and IRPhEP are collaborative efforts that involve numerous scientists, engineers, administrative support personnel, and program sponsors from 24 different countries. The authors would like to acknowledge the efforts of all of these dedicated individuals without whom the ICSBEP and IRPhEP would not be possible. The authors would especially like to acknowledge the evaluators and reviewers of the benchmark data that were published since the ND2007, which are highlighted in this paper.

This paper was prepared at Idaho National Laboratory for the U.S. Department of Energy under Contract Number (DE-AC07-05ID14517).
[1] Pavel Obložinský (Editor), Special Issue on Evaluated $\mathrm{Nu}$ clear Data File ENDF/B-VII.1, Nuclear Data Sheets, Volume 112, Number 12, ISSN 0090-3752, December 2011.

[2] International Handbook of Evaluated Criticality Safety Benchmark Experiments, NEA/NSC/DOC(95)03/I-IX, Organization for Economic Co-operation and Development
- Nuclear Energy Agency (OECD-NEA), September 2012.

[3] International Handbook of Evaluated Reactor Physics Benchmark Experiments, NEA/NSC/DOC(2006)1, Organization for Economic Co-operation and Development Nuclear Energy Agency (OECD-NEA), March 2013. 